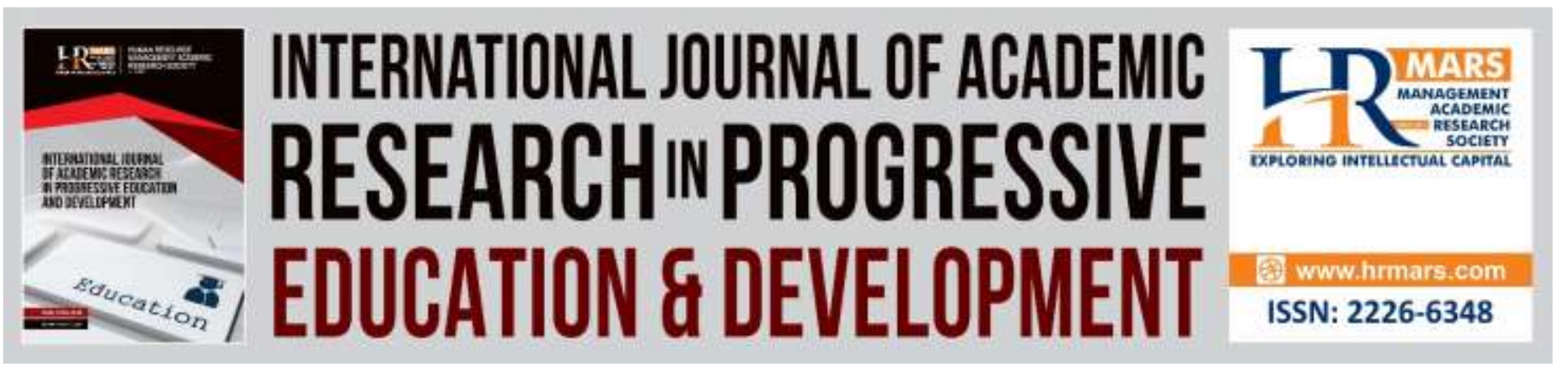

\title{
Professional Learning Communities: A Comparison Study between Day Secondary School and Fully Residential Secondary School in Malaysia
}

Tai Mei Kin \& Omar Abdull Kareem

To Link this Article: http://dx.doi.org/10.6007/IJARPED/v8-i2/5680

DOI: $10.6007 /$ IJARPED/v8-i2/5680

Received: 08 April 2019, Revised: 23 April 2019, Accepted: 05 May 2019

Published Online: 09 May 2019

In-Text Citation: (Kin \& Kareem, 2019)

To Cite this Article: Kin, T. M., \& Kareem, O. A. (2019). Professional Learning Communities: A Comparison Study between Day Secondary School and Fully Residential Secondary School in Malaysia. International Journal of Academic Research in Progressive Education and Development, 8(2), 87-101.

\section{Copyright: (C) 2019 The Author(s)}

Published by Human Resource Management Academic Research Society (www.hrmars.com)

This article is published under the Creative Commons Attribution (CC BY 4.0) license. Anyone may reproduce, distribute, translate and create derivative works of this article (for both commercial and non-commercial purposes), subject to full attribution to the original publication and authors. The full terms of this license may be seen at: $\underline{\text { http://creativecommons.org/licences/by/4.0/legalcode }}$

Vol. 8(2) 2019, Pg. 87 - 101

Full Terms \& Conditions of access and use can be found at http://hrmars.com/index.php/pages/detail/publication-ethics 


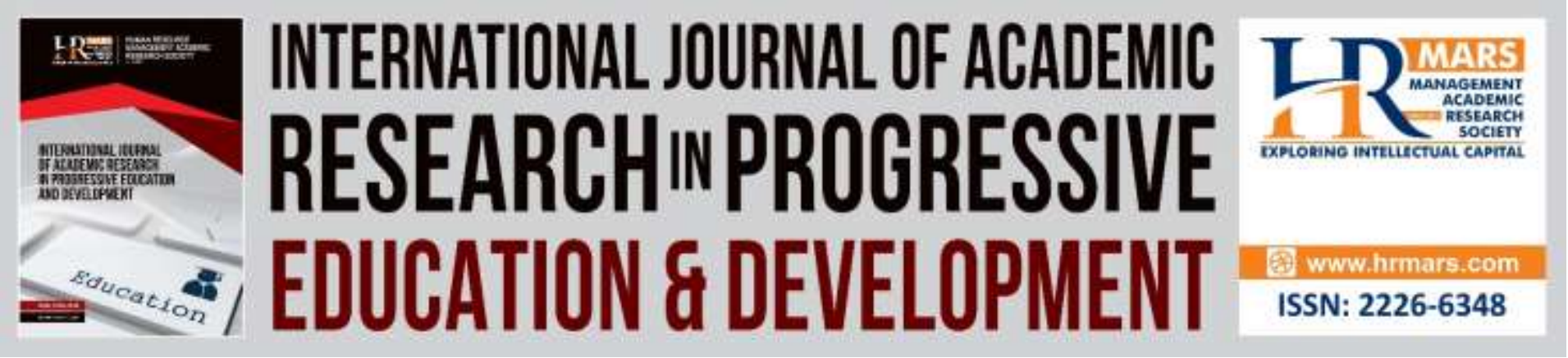

\title{
Professional Learning Communities: A Comparison Study between Day Secondary School and Fully Residential Secondary School in Malaysia
}

\author{
Tai Mei Kin ${ }^{1} \&$ Omar Abdull Kareem² \\ 1,2 Department of Management and Leadership, Faculty of Management and Economics, Sultan \\ Idris Education University, 35900 Tanjong Malim, Perak Darul Ridzuan, Malaysia \\ Email: taimeikin@fpe.upsi.my
}

\begin{abstract}
The purpose of the study was to examine and compare the patterns of professional learning communities (PLCs) in Malaysian day secondary school (DSS) and fully residential secondary school (FRSS). A total of 352 teachers from DSS and 357 from FRSS completed the survey with usable data. The result demonstrated that, i) both DSS and FRSS achieved the level of Quite Good in developing PLCs; ii) FRSS achieved higher level of practising PLCs than DSS and the difference was significant; iii) in terms of dimensions, both DSS and FRSS achieved higher mean score in Organizational Factor than in Non-organizational Factors and the difference was significant; iv) in terms of subdimensions, despite FRSS achieved the level of Good at Principal's Commitment and Support, both DSS and FRSS achieved the level of Quite Good in all other sub-dimensions of PLCs; v) DSS achieved the highest mean score in Shared Norms and Vision whereas FRSS in Principal's Commitment and Support; and vi) both DSS and FRSS achieved the lowest mean score in External Support System. The study contributes to the field of learning organization specifically in providing the first step in advancing more robust and comprehensive analysis in exploring PLCs in Malaysian secondary schools.
\end{abstract}

Keywords: Professional Learning Communities, Shared Norms And Vision, Principal's Commitment And Support; Structural Support, Colleague Understanding And Trust, Collaboration, Reflective Dialogue, Collective Inquiry, External Support System

\section{Introduction}

In the light of globalization, schools are confronted with burgeoning reform agenda to prepare students for the 21st century. However, most education reform efforts have often been short-lived and the benefits marginal. Hence, the sustainability of school improvement has been at the core of school reforms across many countries in the world (Stoll \& Louis, 2007). To address these 
predicaments, a systemic and comprehensive approach to school improvement is needed so that it has a sustained and lasting impact on students.

Among these, developing professional learning communities (PLCs) have emerged as a viable and sustainable option. Indeed, PLCs are viewed as the "best hope for school reform" (Harris, 2010; Hipp \& Huffman, 2010; Pyhalto, Soini \& Pietarinena, 2011) especially in improving teaching quality and student learning (DuFour, Eaker \& Dufour, 2005; Hipp \& Huffman, 2010; Hord \& Sommers, 2008; Louis, 2008; Olivier \& Hipp, Qiao, Yu, Zhang, 2018; 2016; Stoll \& Louis, 2007). As the educational challenge facing many countries is to achieve equal access and higher levels of learning for all students, and the teacher is the single most important school-based determinant of student outcomes (Jensen, 2012; McKinsey \& Company, 2007; Wang, 2015), teacher quality is therefore central to improving education systems. The quality of a school system cannot exceed the quality of its teachers (Barber \& Mourshed, 2007). Promisingly, research on the world's most improved school systems indicates that high-performing teachers can improve student achievement by up to $50 \%$ over a three-year period (Ministry of Education Malaysia, 2013).

In the light of the above, the current paradigm shift in teacher professional development is no longer on supporting the acquisition of knowledge and skills (Vescio, Ross, \& Adams, 2008), but rather, on how teachers play an active role in collectively constructing knowledge on teaching and learning. PLCs are perceived to hold considerable promise for such improvement on teachers, individually and collectively, and act as a lever that supports school-wide capacity for promoting students' learning (Mitchell \& Sackney, 2000; Stoll, Bolam, McMahon, Wallace, \& Thomas, 2006). It has thus gained increasing attention from schools and education systems (DuFour et al., 2005; McLaughlin \& Talbert, 2006; Qiao et al., 2018) and has become a genuine and hot approach for education reform across the world.

The Malaysian education system is undertaking an intensive period of change with the launching of the Malaysia Education Blueprint 2013-2025 (Ministry of Education Malaysia, 2013). While school reforms have targeted the improvement of learning outcomes of all students and their holistic development, and research indicating a significant relationship between PLCs and the improvement in teachers' practice and student achievement (Lomos, Hofman, \& Bosker, 2011; Vescio et al., 2008), there is a dire need to investigate PLCs in the Malaysian school system. In fact, one of the important steps to achieve the objectives of the "Transform Teaching into the Profession of Choice - the 4th shift set out in the Blueprint" (Ministry of Education Malaysia, 2013), is to create and develop a peer-led culture of PLCs. Thus, it is important that in the midst of the implementation of the Blueprint, PLCs are examined as they inform and guide practices, especially teachers to engage change in schools and ultimately to transform the school system successfully.

\section{Professional Learning Communities}

Since the 1990s, the concept of professional learning communities (PLCs) has gained increasing attention in western educational settings (Olivier \& Huffman, 2016). There is widespread belief that PLCs are part of an important strategy to improve teaching and learning, and a significant staff development approach that contributes to whole-school improvement and overall effectiveness (Chen, Lee, Lin \& Zhang, 2016; DuFour et al., 2005; McLaughlin \& Talbert, 2006; Olivier \& Huffman, 2016; Qiao et al., 2018). 
INTERNATIONAL JOURNAL OF ACADEMIC RESEARCH IN PROGRESSIVE EDUCATION AND DEVELOPMENT

Vol. 8, No. 2, 2019, E-ISSN: 2226-6348 @ 2019 HRMARS

Although the conceptualization of PLCs may differ, it is generally viewed as groups of teachers committing themselves to achieve educational goals through shared vision and values, collective responsibility, collaboration and professional learning practices. With improved student learning as a goal, they create a school culture of learning and development so as to maintain and enhance professional knowledge and skills required for the job as they view student learning and achievement as an internal professional responsibility of teachers (Chen etal., 2016; Hipp \& Huffman, 2010;McLaughlin \& Talbert, Zhang \& Pang, 2016).

Generally, concepts and models of PLCs originated from the west are focused predominantly on Anglo-American settings (Zhang \& Pang, 2016). Nevertheless, whether the understanding and conceptualization of PLCs are derived from western educational settings can be generalized across eastern educational territory needs to be explored in-depth. This is particularly true as accumulating research evidence indicates that PLCs practices are found embedded in cultural and organizational contexts and enacted differently in diversified contexts (Hairon \& Dimmock, 2012). Malaysian schools appear to have some key processes of PLCs as described in the western literature, yet the forms and structures seem to be somewhat different as the historical and cultural contexts, and the Malaysian educational system are all different from those in western countries.

In 2018, Tai, Omar and Ghouri (2018) developed Professional Learning Communities Scale (PLCS) based on Malaysian school settings to measure local PLCs. This instrument consists of two main dimensions i.e. Organizational Factor and Non-organizational Factor. Organizational Factor encompasses four sub-dimensions namely, (a) Shared Norms and Vision; (b) Principal's Commitment and Support; (c) Structural Support; and (d) Collegial Understanding and Trust. Shared Norms and Vision refers to the extent to which school members share visions pertaining to student learning, pedagogical purpose, school improvement and effectiveness and support norms of behaviours that guide decisions about the concerned purposes. School principal's Commitment and Support is viewed as the extent to which school principal support and committed to the development and enhancement of PLCs in school and will take optimal steps to face any obstacles. Structural Support means the extent to which the administrative system, procedures and policies support the development and enhancement of PLCs in terms of time arrangement, space, facilities, resources and funding. Collegial Understanding and Trust refer to the extent to which school members develop mutual understanding and respect, trust, mindful and caring relationships that facilitate group processes to solve problems, make decisions and promote change (Tai et al., 2018).

Non-organizational Factor also consists of four sub-dimensions namely, (a) Collaborative Learning; (b) Reflective Dialogue; (c) Collective Inquiry; and (d) External Support System (Tai et al., 2018). Collaborative Learning is seen as the extent to which the teacher practise collaborative learning that includes constantly sharing information, resources and works collaboratively to plan, solve problems, strengthen teaching practice and improve student learning. Reflective Dialogue means the maintenance of a dialogue journal or participation in reflective conversations in groups or pairs that might help the teacher gain new insights about teaching practices, and the perspectives are usually shared in an atmosphere of mutual support. Collective Inquiry is viewed as the extent to which school encourages the staff in building shared knowledge by examining systematically and collectively their educational practices and impact. External Support System means improving outreach and collaboration with stakeholders including families, communities, 
INTERNATIONAL JOURNAL OF ACADEMIC RESEARCH IN PROGRESSIVE EDUCATION AND DEVELOPMENT

Vol. 8, No. 2, 2019, E-ISSN: 2226-6348 @ 2019 HRMARS

district and state education departments, in the process of developing and promoting PLCs in schools (Tai et al., 2018).

\section{Methodology}

Sample

For comparison purposes, data was collected from day secondary school (DSS) and fully residential secondary school (FRSS) in Malaysia. To perform the test adequately, all the 16 states and federal territories in Malaysia were involved in the study. As shown in Table 1, for each state/federal territory, two DSS and FRSS were chosen randomly for the survey respectively, giving a total of 64 schools $(32 \times 2)$ engaged in the survey. In each school, 15 teachers were chosen as respondents at random. In other words, there were 480 teachers $(32 \times 15)$ of DSS and FRSS selected randomly for the survey respectively or a total of 960 respondents engaged in the study.

Table 1. Total number of schools and respondents involved in the survey

\begin{tabular}{lccccc}
\hline \multicolumn{1}{c}{ Types of school } & $\begin{array}{c}\text { No. of } \\
\text { schools } \\
\text { involved }\end{array}$ & $\begin{array}{c}\text { No. of } \\
\text { teachers } \\
\text { involved } \\
\text { in each } \\
\text { school }\end{array}$ & $\begin{array}{c}\text { Total no. } \\
\text { of } \\
\text { teachers } \\
\text { involved }\end{array}$ & $\begin{array}{c}\text { No. of } \\
\text { questionnaires } \\
\text { returned }\end{array}$ & $\begin{array}{c}\text { Usable } \\
\text { data }\end{array}$ \\
\hline $\begin{array}{l}\text { Day Secondary } \\
\text { School }\end{array}$ & 32 & 15 & 480 & 363 & 352 \\
$\begin{array}{l}\text { Fully Residential } \\
\text { School }\end{array}$ & 32 & 15 & 480 & 366 & 357 \\
\hline Total & 64 & 30 & 960 & 729 & 709 \\
\hline
\end{tabular}

\section{Survey Instrument}

PLCs were measured by using Professional Learning Communities Scale (PLCS) developed by Tai et al. (2018) in the Malaysian education setting. This instrument consists of 63 items and provides evidence for convergent validity as the Squared Multiple Correlations (SMC) are all above the recommended acceptance level, 0.5. (Hair, Black, Babin, \& Anderson, 2010; Holmes-Smith, 2001), the Average Extracted Value (AVE) all surpassed 50\% (Fornell \& Larker, 1981), and the Composite Reliability Index (CRI) exceeded 0.70 the rule of thumb (Hair et al., 2010). Besides, it also held discriminant validity since AVE of the factors is greater than 0.50 (Hair et al., 2010; Kline, 2011) and Composite Reliability Index is greater than 0.70 (Hair et al., 2006).

The instrument is a six-point Likert-type scale and respondents are requested to rank their responses from "strongly disagree" to "strongly agree". The main content of the questionnaire consisted of two major parts. Part I contained demographic information such as gender, age, race, highest education level, years in present job and type of school. Part II consisted of scale items of PLCs. The data interpretation for the level of PLCs is based on the measurement and two indicators i.e. frequency of the performance and performance rating as shown in Table 2. 
INTERNATIONAL JOURNAL OF ACADEMIC RESEARCH IN PROGRESSIVE EDUCATION AND DEVELOPMENT

Vol. 8, No. 2, 2019, E-ISSN: 2226-6348 @ 2019 HRMARS

Table 2. Raw Scores of PLCS and Its level and indicators

\begin{tabular}{llll}
\hline Raw Scores & Level of PLCs & \multicolumn{2}{c}{ Indicators } \\
& & $\begin{array}{l}\text { Frequency of the } \\
\text { Performance }\end{array}$ & Performance \\
& & Rating \\
\hline $5.51-6.00$ & Very good & Often all of the time & Very satisfactory \\
$5.01-5.50$ & Good & Quite Often & Satisfactory \\
$4.01-5.00$ & Quite good & Sometimes & Quite satisfactory \\
$3.01-4.00$ & Fair & Quite Rarely & Average \\
$2.01-3.00$ & Quite poor & Rarely & Quite \\
$1.51-2.00$ & Poor & & Dissatisfactory \\
& & Almost Never & Dissatisfactory \\
$1.00-1.50$ & Very poor & & Very \\
& & & Dissatisfactory \\
\hline
\end{tabular}

\section{Data Analysis}

A total of 960 sets of questionnaires were sent out via post and eventually 729 sets were returned, with a response rate of $75.94 \%$ (Table 1). Twenty sets of questionnaires were excluded from further analysis, as there were illegible responses or unaccepted errors. In summary, a total of 709 sets of questionnaires were included for the final analysis; this included 352 sets from DSS and 357 from FRSS. Descriptive statistical analysis was employed in the study whereby data was computed to obtain mean scores and percentages. The $t$-test and one-way analysis of variance (ANOVA) were also employed to test the significance of the differences on the concerned variables based on the significance level of .05.

\section{Demographic characteristics}

Of the respondents completing the questionnaires, 30.32\% ( $\underline{N}=215$ ) were male and $69.68 \%$ $(\underline{N}=231)$ were female. There were $41.04 \%(\underline{N}=291)$ in the age group of 31 to 40 years, $28.07 \%$ $(\underline{N}=199)$ of the ages of 41 to 50 years, $19.32 \%(\underline{N}=137) 51$ to 60 years and $11.57 \%(\underline{N}=82) 21$ to 30 years. Most of the respondents or $91.11 \%$ had a Bachelor's degree ( $\underline{N}=646$ ), followed by $8.32 \%$ respondents with a Master's degree $(\underline{N}=59)$ and only $.57 \%$ of the respondents had a Ph.D. degree $(\underline{N}=4)$. Besides, most of the respondents or $25.67 \%(\underline{N}=182)$ had worked more than 20 years, $22.57 \%$ ( $\underline{N}=160$ ) worked between 6 to 10 years, 20.31\% ( $\underline{N}=144) 11$ to 15 years, 15.79\% ( $\underline{N}=112) 1$ to 5 years and $15.66 \%(\underline{N}=111)$ had worked 16 to 20 years. A total of $50.35 \%(\underline{N}=357)$ of the respondents were from FRSS and $49.65 \%(\underline{N}=352)$ were from DSS.

\section{Findings}

As shown in Figure 1, the mean score of PLCs for DSS was 4.59 and FRSS was 4.86. Based on the raw scores and the level of PLCs displayed in Table 2, both the teachers of DSS and FRSS also rated their school as Quite Good in PLCs as the mean scores fell within 4.01 to 5.00, respectively. In fact, a difference of .27 was observed between the above mean scores and the difference was significant. This was affirmed by the result of $t$-test, $t=-6.671, \mathrm{df}=706, \mathrm{p}<.05$ (Table 3 ). 
In terms of dimension, Figure 1 reveals that the level of Organizational Factors of FRSS $(M=4.92)$ was higher than those of DSS $(M=4.64)$; with both also achieved the level of Quite Good as the mean scores raging from 4.01 to 5.00. Obviously there was significant difference of means, $t=-6.529, d f=707, p<.05$ (Table 3). Similarly, the level of Non-organizational Factors of FRSS $(\mathrm{M}=4.81)$ was higher than those of DSS $(\mathrm{M}=4.54)$, and both achieved the level of Quite Good. A difference of .27 was observed between the two mean scores and the difference was significant, $\mathrm{t}=-6.205, \mathrm{df}=706, \mathrm{p}<.05$ (Table3). Comparatively, both DSS and FRSS also achieved higher mean score in Organizational Factors (M4.64 [DSS]; $M=4.92$ [FRSS]) than Non-organizational Factors ( $M=4.54$ [DSS]; $M=4.81$ [FRSS]) (Figure 1), respectively.

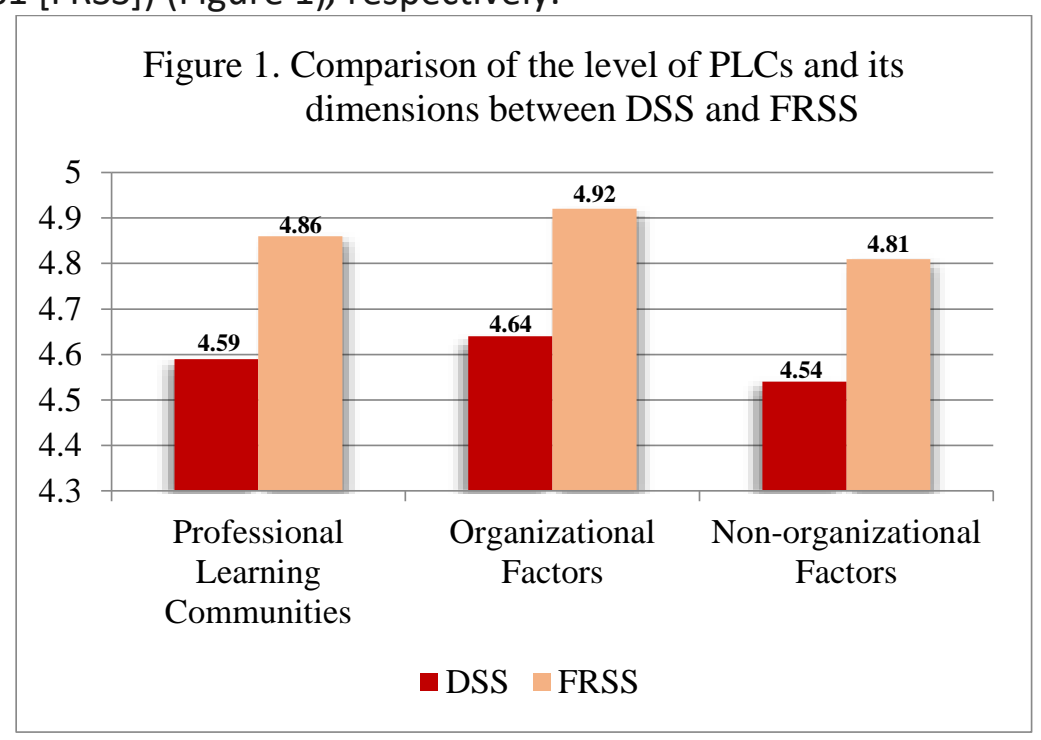

Table 3. Independent sample t-Test for differences among dimensions and sub-dimensions of PLCs between DSS and FRSS

\begin{tabular}{|c|c|c|c|c|c|c|}
\hline $\begin{array}{c}\text { PLCs and its } \\
\text { dimension/ } \\
\text { Sub-dimension }\end{array}$ & Variance & $F$ & Sig. & $t$ & $d f$ & $\begin{array}{l}\text { Sig. } \\
(2- \\
\text { tailed }\end{array}$ \\
\hline $\begin{array}{l}\text { Professional } \\
\text { Learning }\end{array}$ & $\begin{array}{l}\text { Equal variances } \\
\text { assumed }\end{array}$ & .065 & .799 & -6.671 & 706 & .000 \\
\hline Communities & $\begin{array}{l}\text { Equal variances not } \\
\text { assumed }\end{array}$ & & & -6.672 & 705.952 & .000 \\
\hline \multirow[t]{2}{*}{$\begin{array}{l}\text { Organizational } \\
\text { Factor }\end{array}$} & $\begin{array}{l}\text { Equal variances } \\
\text { assumed }\end{array}$ & .022 & .883 & -6.529 & 707 & .000 \\
\hline & $\begin{array}{l}\text { Equal variances not } \\
\text { assumed }\end{array}$ & & & -6.530 & 706.963 & .000 \\
\hline $\begin{array}{l}\text { Non- } \\
\text { organizational }\end{array}$ & $\begin{array}{l}\text { Equal variances } \\
\text { assumed }\end{array}$ & .196 & .658 & -6.205 & 706 & .000 \\
\hline Factor & $\begin{array}{l}\text { Equal variances not } \\
\text { assumed }\end{array}$ & & & -6.205 & 705.517 & .000 \\
\hline $\begin{array}{l}\text { Shared Norms and } \\
\text { Vision }\end{array}$ & $\begin{array}{l}\text { Equal variances } \\
\text { assumed }\end{array}$ & .076 & .783 & -3.597 & 707 & .000 \\
\hline
\end{tabular}


INTERNATIONAL JOURNAL OF ACADEMIC RESEARCH IN PROGRESSIVE EDUCATION AND DEVELOPMENT

Vol. 8, No. 2, 2019, E-ISSN: 2226-6348 @ 2019 HRMARS

\begin{tabular}{|c|c|c|c|c|c|c|}
\hline & $\begin{array}{l}\text { Equal variances not } \\
\text { assumed }\end{array}$ & & & -3.600 & 699.035 & .000 \\
\hline \multirow{2}{*}{$\begin{array}{l}\text { Principal's } \\
\text { Commitment } \\
\text { and Support }\end{array}$} & $\begin{array}{l}\text { Equal variances } \\
\text { assumed }\end{array}$ & 4.324 & .038 & -6.694 & 707 & .000 \\
\hline & $\begin{array}{l}\text { Equal variances not } \\
\text { assumed }\end{array}$ & & & -6.690 & 700.817 & .000 \\
\hline \multirow[t]{2}{*}{ Structural Support } & $\begin{array}{l}\text { Equal variances } \\
\text { assumed }\end{array}$ & .782 & .377 & -7.531 & 707 & .000 \\
\hline & $\begin{array}{l}\text { Equal variances not } \\
\text { assumed }\end{array}$ & & & -7.528 & 704.170 & .000 \\
\hline \multirow{2}{*}{$\begin{array}{l}\text { Colleague } \\
\text { Understanding } \\
\text { and Trust }\end{array}$} & $\begin{array}{l}\text { Equal variances } \\
\text { assumed }\end{array}$ & 1.443 & .230 & -3.807 & 707 & .000 \\
\hline & $\begin{array}{l}\text { Equal variances not } \\
\text { assumed }\end{array}$ & & & -3.807 & 706.699 & .000 \\
\hline \multirow[t]{2}{*}{ Collaboration } & $\begin{array}{l}\text { Equal variances } \\
\text { assumed }\end{array}$ & .781 & .377 & -4.238 & 707 & .000 \\
\hline & $\begin{array}{l}\text { Equal variances not } \\
\text { assumed }\end{array}$ & & & -4.238 & 706.959 & .000 \\
\hline \multirow[t]{2}{*}{$\begin{array}{l}\text { Reflective } \\
\text { Dialogue }\end{array}$} & $\begin{array}{l}\text { Equal variances } \\
\text { assumed }\end{array}$ & 2.371 & .124 & -4.009 & 707 & .000 \\
\hline & $\begin{array}{l}\text { Equal variances not } \\
\text { assumed }\end{array}$ & & & -4.006 & 699.957 & .000 \\
\hline \multirow[t]{2}{*}{ Collective Inquiry } & $\begin{array}{l}\text { Equal variances } \\
\text { assumed }\end{array}$ & 2.351 & .126 & -4.879 & 706 & .000 \\
\hline & $\begin{array}{l}\text { Equal variances not } \\
\text { assumed }\end{array}$ & & & -4.879 & 705.776 & .000 \\
\hline \multirow[t]{2}{*}{$\begin{array}{l}\text { External Support } \\
\text { System }\end{array}$} & $\begin{array}{l}\text { Equal variances } \\
\text { assumed }\end{array}$ & 1.939 & .164 & -8.150 & 707 & .000 \\
\hline & $\begin{array}{l}\text { Equal variances not } \\
\text { assumed }\end{array}$ & & & -8.144 & 697.797 & .000 \\
\hline
\end{tabular}

A close examination by sub-dimension, as shown in Figure 2, despite FRSS achieving the level of Good in Principal's Commitment and Support, both DSS and FRSS achieved the level of Quite Good in all the other sub-dimensions of PLCs as all the mean scores fell within 4.01 to 5.00. Figure 2 also demonstrated that FRSS achieved higher mean score than those of DSS in the subdimensions of Shared Norms and Vision (4.95>4.78), Principal's Commitment and Support (5.07>4.71), Structural Support (4.74>4.33), Colleague Understanding and Trust (4.90>4.72), Collaboration (4.93>4.72), Reflective Dialogue (4.74>4.53), Collective Inquiry (4.92>4.70), and External Support System (4.67>4.19). Importantly, the differences were significant, as all the pvalues of the $t$-tests were less than .05 (Table 3). Comparatively, among all the sub-dimensions of PLCS, DSS achieved the highest mean score in Shared Norms and Vision $(M=4.78)$ and FRSS in Principals' Commitment and Support $(\mathrm{M}=5.07)$. However, both DSS and FRSS also achieved the lowest mean score in External Support System ( $M=4.19$ [DSS]; $M=4.67$ [FRSS]). 


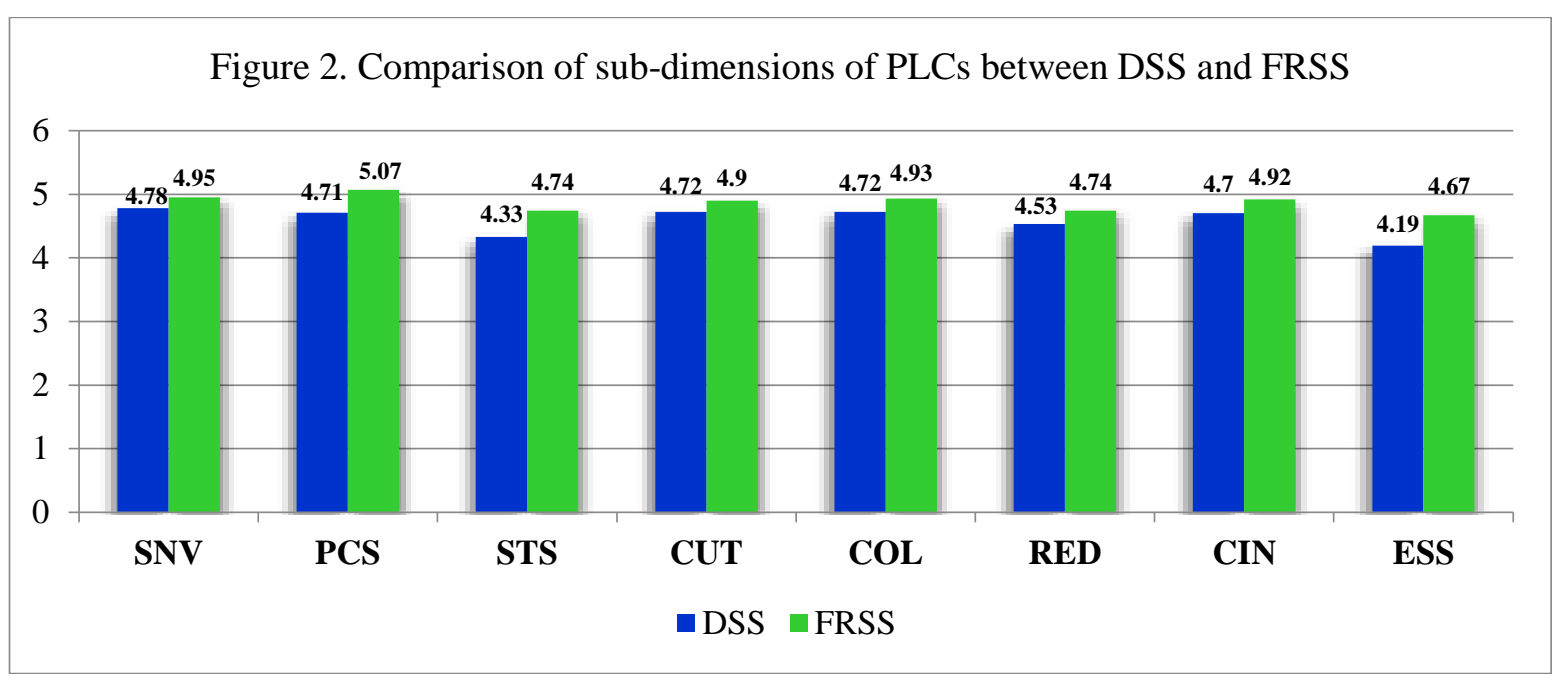

Note. SNV=Shared Norms and Vision; PCS=Principals' Commitment and Support; STS=Structural Support; CUT=Colleague Understanding and Trust; $\mathrm{COL}=$ Collaboration; RED=Reflective Dialogue; CIN=Collective Inquiry; ESS=External Support System; DSS=Day Secondary School; FRSS=Fully Residential Secondary School

ii) FRSS achieved a higher level of practising PLCs than DSS in terms of dimensions and sub-dimensions of PLCs and the differences were significant;

iii) In terms of dimensions of PLCs, both DSS and FRSS achieved higher mean scores in Organizational Factor than Non-organizational Factors and the difference was significant.;

iv) In terms of the sub-dimensions of PLCs, despite FRSS achieving the level of Good in Principal's Commitment and Support, both DSS and FRSS achieved the level of Quite Good in all the other sub-dimensions of PLCs;

v) Among all the sub-dimensions of PLCS, DSS achieved the highest mean score in Shared Norms and Vision whereas FRSS in Principals' Commitment and Support;

vi) Both DSS and FRSS achieved the lowest mean score in External Support System.

\section{Discussion}

From the findings outlined above, the study has unveiled several important insights. First, the result of the study revealed that both DSS and FRSS achieved the level of Quite Good in developing PLCs. Simply put, both teachers of DSS and FRSS had practised PLCS quite often with quite satisfied performance (Table 2). This implies that the level of practising PLCs in DSS and FRSS is yet to be enhanced if it is to be effective in the process of addressing school reform. In other words, there is room for improvement for teachers of DSS and FRSS to enhance their professional learning and practices to promote student learning. As mentioned earlier, developing a peer-led culture of PLCS is one of the important steps in achieving the objectives of "Transform Teaching into the Profession of Choice - the 4th shift set out in the Blueprint" (Ministry of Education Malaysia, 2013). Therefore, concerted efforts need to be taken by the Ministry of Education Malaysia to identify the root course of the above predicament. Equally important, school leaders as the main administrators in schools need to ensure the incorporation and enhancement of PLCs practices in schools as PLCs surfaced 
INTERNATIONAL JOURNAL OF ACADEMIC RESEARCH IN PROGRESSIVE EDUCATION AND DEVELOPMENT

Vol. 8, No. 2, 2019, E-ISSN: 2226-6348 @ 2019 HRMARS

as a viable and sustainable option for school improvement and effectiveness (Olivier \& Huffman, 2016; Pang, Wang \& Leung, 2016; Zhang \& Pang, 2016).

Secondly, FRSS achieved higher level of practicing PLCS as compared to DSS in terms of dimensions and sub-dimensions, and the differences were significant. One potential reason to explain the above result is that different organizational culture shapes different levels of PLCs. Substantial research has indicated that PLCs practices are found embedded in cultural and organizational contexts (Chen et al., 2016; Hairon \& Dimmock, 2012; Lee \& Kim, 2016; Olivier \& Huffman, 2016; Pang et al., 2016; Zhang \& Pang, 2016). Although DSS and FRSS are secondary schools in Malaysia, there are differences in organizational culture. Basically, DSS is the most popular type of secondary schools in Malaysia. It makes up 85\% of the secondary schools in this country. FRSS are schools to increase the opportunities for indigenous students to receive quality education in preparation for higher education to fulfil national needs. Hence FRSS provide students with better education resources, complete and updated facilities that are conducive to a healthy school culture (Tai \& Omar, 2014; Tai \& Omar, 2016). As the functions of these two types of school are entirely different, the anatomy of these different school cultures - the beliefs, shared values, work styles and relationships, is different and can influence the implementation of PLCs in different ways. Notably, the practice of PLCs is largely influenced by contextual factors (Hairon \& Dimmock, 2012; Zhang \& Pang, 2016); this should not come as a surprise that FRSS achieved higher level of practicing PLCs than DSS.

Thirdly, in terms of dimensions of PLCs, both DSS and FRSS achieved higher mean scores in Organizational Factor than Non-organizational Factor and the difference was significant. In this study we conceptualized that PLCs can be operationalized at the organizational school level and the non-organizational level. At the organizational school level, as mentioned earlier, we refer to how school leaders support the practice of PLCs in terms of Shared Norms and Vision, Principal's Commitment and Support, Structural Support and Collegial Understanding and Trust; at the nonorganizational level, we refer to how teacher perform PLCs in terms of Collaborative Learning, Reflective Dialogue and Collective Inquiry and how various stakeholders and the local community support PLCs through External Support System.

Based on the result that both DSS and FRSS achieved higher mean scores in Organizational Factor than Non-organizational Factor, this implies that teachers of DSS and FRSS had higher perception of Organizational Factor than Non-organizational Factor in the development of PLCs. For example, teachers of DSS and FRSS might perceive that their school leaders were more likely to share power, authority, promote a distributed form of leadership, support norms of behaviour that guide decisions about teaching and learning, arrange time, provide space, coordinate resources, develop mutual respect, trust and caring relationship in the processes of developing PLCs in schools (Tai et al., 2018). This perception indirectly revealed that the school management not only emphasized the cultivation and development of leadership abilities at different levels in promoting teacher learning and facilitating improvements in instruction, they also valued the importance of continuous professional development of teachers in enhancing their efficacy and capacity for teaching, and creating a positive organizational climate for improving student outcomes in school transformation. In brief, they were attentive and supportive in the process of developing and promoting PLCs in schools. 
INTERNATIONAL JOURNAL OF ACADEMIC RESEARCH IN PROGRESSIVE EDUCATION AND DEVELOPMENT

Vol. 8, No. 2, 2019, E-ISSN: 2226-6348 @ 2019 HRMARS

Comparatively, teachers of DSS and FRSS might perceive themselves as not doing so good in Non-organizational Factor, which includes shared practices such as Collaborative Learning, Reflective Dialogue and Collective Inquiry on improving operational effectiveness of PLCs. The above initiatives are preconditions for teachers to learn from one another to improve instructional practices. Hence, if teachers were not fond of working collaboratively on the above shared practices, they were more likely to be reluctant to work together often to determine the best way to implement changes in the classroom. This would make it difficult to allow students to approach learning in more authentic and interdisciplinary ways, thus minimizing learning impact. Meanwhile, teachers of DSS and FRSS might perceive that the level of External Support System is yet to be improved, as it is also accountable for the learning outcomes of the students. Indeed, it has the ability to nourish and sustain highly effective PLCs in schools, specifically in facilitating teachers' collaborative learning, linking to professional network and teacher professional development (Olivier \& Huffman, 2016). All these collaborative initiatives promote shared responsibility and is a source of assistance that can help in achieving desired student-learning results.

Fourthly, a close examination in terms of the sub-dimensions of PLCs revealed that despite FRSS achieving the level of Good in Principal's Commitment and Support, both DSS and FRSS achieved the level of Quite Good in all the other sub-dimensions of PLCs. This implies that despite Principal's Commitment and Support, most of the time DSS and FRSS had only practised PLCs quite often with quite satisfied performance (Table 2). Unarguably there is a need for teachers of DSS and FRSS to enhance their professional practices to build up effective PLCs. In this respect, concerted efforts need to be taken by the Ministry of Education Malaysia to examine the situation as mentioned earlier, as the findings may provide practical insights for relevant parties such as the Institut Aminuddin Baki, and teacher training institutions in Malaysia that develop and conduct training courses for school leaders and teachers, respectively. This sharpened understanding of the different sub-dimensions of PLCs would help them customise courses that may help school leaders and teachers to nurture and sustain a positive organizational culture that is crucial for the development and effective practice of PLCs in schools.

Fifthly, among all the sub-dimensions of PLCs, DSS achieved the highest mean score in Shared Norms and Vision whereas FRSS in Principal's Commitment and Support. Shared Norms and Vision refer to the associated teachers of a school being committed to the ultimate objectives, rules and norms on student accomplishment. This feeling of share vision has substantial benefits of a collaborative nature that positively affects the implementation of PLCs in a school. DSS achieved the highest mean score in Shared Norms and Vision and indicated that the practice of sharing norms and vision were encouraging such that teachers of DSS developed together the school vision; a range of strategies had been considered by the teachers in determining how to achieve the school vision; the teachers had a clear direction of how to turn school vision into reality; the school management used possible means to communicate the vision to create full understanding; the teachers were constantly engaged in decision making in alignment with the school vision; responsibilities were shared amongst the teachers to achieve the school vision; the teachers were actively involved in communication to continually reinforce the vision; and programmes implemented by teachers were aligned to the school's vision (Tai et al., 2018). The above initiatives 
would align teachers to achieve mutual objectives that create a culture open to learn and share for the teacher as well as in enhancing student learning.

On the other hand, the findings demonstrated that FRSS achieved the highest mean score in Principal's Commitment and Support. Indeed, to introduce and nourish the idea of PLCs in schools would entail the school principals' hard work and commitment. The focus would be on creating opportunities to engage teachers in decision making about student learning, encouraging teachers to share best practices about effective teaching, providing emotional support when teachers face problems in student learning, providing opportunities for communication across departments in enhancing student learning, devoting sufficient time to settle potential problems pertaining to student learning, providing constructive feedback for teachers through constant class observation, using every possible means to help teachers to teach at their best, and giving recognition to those teachers who strive toward the realization of effective teaching (Tai et al., 2018). If school principals fail to engage in these, effective implementation of PLCs concept would not to be successful. FRSS achieved the highest mean score in Principal's Commitment and Support, which indicated that teachers of FRSS believe that the commitment and support of their school principals for developing PLCs in schools were sufficient and relevant. It is highly likely that to a large extent, this would influence a positive evaluation of teachers toward the initiatives that would ultimately encourage teachers to engage actively in developing and promoting PLCs in schools.

Sixthly, the study also revealed that both DSS and FRSS achieved the lowest mean score in External Support System. This finding was aligned with the third finding that teachers of DSS and FRSS perceived themselves as not doing so good in Non-organizational Factor which includes how various stakeholders and the local community support PLCs through External Support System. This indicated that there is room for improvement for collaboration between schools and various stakeholders to promote PLCs in schools. These may include the local communities that provide financial support for the improvement of school facilities, parents who are willing to cooperate with the school to take effective initiatives for intentional student improvement, the Old Boys or Old Girls Associations are active supporters in providing assistance in continuous school improvement, the Parent-Teacher Association are active promoters of the shared responsibility for student learning, sustained communication about student learning being available between school management and the stakeholders, partnerships between schools help teachers share solutions to commonly faced problems in teaching practice, and district or state education departments providing high quality professional development programmes for teachers (Tai et al., 2018). As both DSS and FRSS achieved the lowest mean score in External Support System, school leaders play an important role in promoting the shared responsibility effectively among various stakeholders in maximizing the practice of PLCs in schools.

\section{Limitations and Future Direction of the Study}

In the light of this study, several limitations and future directions for research were identified and briefly discussed. To avoid egocentric biases and to gain a more comprehensive view, it would be good to collect the data from school principals and senior assistants as well, rather than from teachers alone. This will certainly allow the researchers to gain a multidimensional perspective of the phenomenon and to enhance the ability to interpret the findings. Besides, in order to increase the generalizability of the findings, it would be meaningful if similar research could be done using 
a larger sample, as well as across different samples. Lastly, the assumption made in the present study regarding the relationship between organizational culture and the different levels of PLCS achieved by DSS and FRSS respectively has to be investigated further by using the concerned instrument to identify the extent of the impact of organizational culture upon PLCs. Any future study to obtain such data would greatly advance our understanding of the phenomena under study.

\section{Conclusion}

The different patterns of PLCs presented in this study will enrich and expand our understanding and learning about the process of creating, developing and sustaining effective PLCs in Malaysian secondary schools. Basically there is room for improvement in developing PLCs in DSS and FRSS and appropriate strategies need to be adopted by the Ministry of Education Malaysia as well as the school leaders in coping with challenges arising from the development and practice of PLCs in schools. Secondly, we cannot underestimate the fact that organizational culture contributes to the effective development of PLCs, and that peer-led learning is influenced by contextual factors; these may be critical factors that impact the practices of PLCs in DSS and FRSS. Thirdly, much attention needs to be paid on Non-organizational Factor than Organizational Factor in developing effective PLCs in DSS and FRSS, specifically on teacher professionalism and collaborative learning in the process of promoting student learning. Fourthly, the development and sustainability of PLCs are dependent, not only on the organizational factor, but also on external influencing factors and stakeholders; thus school leaders need to have a profound understanding of how to promote shared responsibility effectively among various stakeholders in developing and sustaining the embedded PLCs process within schools.

In summary, this empirical study would shed light on the enhancement of teacher professional practice and student learning, and provide practical insights for educational researchers and practitioners in advancing a more comprehensive analysis in exploring PLCs towards continuous and sustained school improvement. As a whole, this study contributes to the field of learning organization whereby effective professional development will strengthen teachers' capacity to advance change and innovation which in turn results in improvement to student learning. It serves as an important step forward for organizational studies that may help move the learning organizational literature to a more coherent theoretical perspective.

\section{Acknowledgements}

This work was supported by the University Special Research Grant Scheme (Fundamental) (Code: 2017-0196-107-01), Sultan Idris Education University, Malaysia.

\section{References}

Barber, M., \& Mourshed, M. (2007). How the World's Best Performing Systems come out on top. Mckinsey \& Company. Retrieved from https://www.mckinsey.com/industries/socialsector/our-insights/how-the-worlds-best-performing-school-systems-come-out-on-top

Chen, C., Lee, C, Lin, H., \& Zhang, C. (2016). Factors that develop effective professional learning communities in Taiwan. Asia Pacific Journal of Education, 36(2), 248-265. doi: 10.1080/02188791.2016.1148853 
INTERNATIONAL JOURNAL OF ACADEMIC RESEARCH IN PROGRESSIVE EDUCATION AND DEVELOPMENT

Vol. 8, No. 2, 2019, E-ISSN: 2226-6348 @ 2019 HRMARS

DuFour, R., Eaker, R., \& DuFour, R. (2005). On common ground: The power of professional learning communities. Bloomington: Solution Tree.

Fornell, C., \& Larcker, D. (1981). Structural Equation Models with unobservable variables and measurement error: Algebra and statistics. Journal of Marketing Research, 18(August),

382-388.

Hair, J. F., Black, W. C., Babin, B. J., \& Anderson, R. E. (2010). Multivariate data analysis: A global perspective. New Jersey: Pearson Prentice Hall.

Hairon, S., \& Dimmock, C. (2012). Singapore schools and professional learning communities:

Teacher professional development and school leadership in an Asian hierarchical system.

Educational Review, 64(4), 405-424.

Harris, A. (2010). Leading system transformation. School Leadership and Management, 30(30), 197-207.

Hipp, K. K., \& Huffman, J. B. (2010). Demystifying the concept of professional learning communities. In K. K. Hipp \& J. B. Huffman (Eds.), Demystifying professional learning communities: School

leadership at its best (pp. 11-22). New York, NY: Rowman \& Littlefield Education.

Holmes-Smith, P. (2001). Introduction to Structural Equation Modelling using LISREAL. Perth: ACSPRI-Winter Training Program.

Hord, S.M., \& Sommers, W.A. (2008). Leading professional learning communities: Voices from research and practice. Thousand Oaks: Corwin Press.

Jensen, B. (2012). Catching up: Learning from the best school systems in East Asia. Sydney: Grattan Institute.

Kline, R.B. (2011). Principles and practice of Structural Equation Modelling (3 ${ }^{\text {rd }}$ ed.). New York, NY: Guilford.

Lee, M., \& Kim, J. (2016). The emerging landscape of school-based professional learning communities in South Korean schools. Asia Pacific Journal of Education, 36(2), 266-284.

Lomos, C., Hofman, R. H., \& Bosker, R. J. (2011). Professional communities and student

achievement A meta-analysis. School Effectiveness and School Improvement, 22(2), 121-148.

Louis, K. S. (2008). Creating and sustaining professional communities. In A. M. Blankstein, P. D. Houston, \& R. W. Cole (Eds.), Sustaining professional learning communities (pp. 41-57). Thousand Oaks, CA: Corwin Press.

McLaughlin, M. W., \& Talbert, J. E. (2006). Professional communities and the work of high school teaching (2nd ed.). Chicago, IL: University of Chicago Press.

Ministry of Education Malaysia. (2013). Malaysia Education Blueprint 2013-2025. Putrajaya:

Ministry of Education Malaysia.

Mitchell, C., \& Sackney, L. (2000). Profound improvement: Building capacity for a learning community. Lisse: Swets \& Zeitlinger.

Olivier, D.F., \& Hipp, J.B. (2016). Professional learning community process in the United States: Conceptualization of the process and district support for schools. Asia Pacific Journal of Education, 36(2), 301-317.

Olivier, D. F., \& Huffman, J. B. (2016). Professional learning community process in the United States: Conceptualization of the process and district support for schools. Asia Pacific Journal of Education, 36(2), 301-317. 
INTERNATIONAL JOURNAL OF ACADEMIC RESEARCH IN PROGRESSIVE EDUCATION AND DEVELOPMENT

Vol. 8, No. 2, 2019, E-ISSN: 2226-6348 C 2019 HRMARS

Pang, N. S., Wang, T., \& Leung, L. (2016). Educational reforms and the practices of professional learning community in Hong Kong primary schools. Asia Pacific Journal of Education, 36(2), 231-247.

Pyhalto, K., Soini, T., \& Pietarinena, J. (2011). A systemic perspective on school reform: Principals' and chief education officers' perspectives on school development. Journal of Educational Administration, 49(1), 46-61.

Qiao, X., Yu, S., \& Zhang, L. (2018). A review of research on professional learning communities in mainland China (2006-2015): Key findings emerging themes. Educational Management Administration and Leadership, 46(5), 713-728. doi: 10.1177/1741143217707523

Stoll, L., Bolam, R., McMahon, A., Wallace, M., \& Thomas, S. (2006). Professional learning communities: A review of the literature. Journal of educational change, 7(4), 221-258.

Stoll, L., \& Louis, K. S. (2007). Professional learning communities: Divergence, depth and dilemmas (1st ed.). Maidenhead: Open University Press.

Tai, M.K., \& Omar, A.K. (2014). Teacher attitudes toward change: A study in Malaysian high performing secondary school. Middle-East Journal of Scientific Research, 21(3), 543-549.

Tai, M.K., \& Omar, A.K. (2016). Teacher attitudes toward Change: A comparison between high- and mediocre- performing secondary schools in Malaysia. International Studies in Educational Administration, 41(1), 105-128.

Tai, M.K., Omar, A.K., \& Ghouri, A.M. (2018). Developing a preliminary model onprofessional learning community in Malaysian secondary school (Unpublished research report which was funded by Fundamental Research Grant Scheme [Code: 2017-0196-107-01], Ministry of Higher Education Malaysia). Sultan Idris Education University, Perak Darul Ridzuan, Malaysia.

Vescio, V., Ross, D., \& Adams, A. (2008). A review of research on the impact of professional learning communities on teaching practice and student learning. Teaching and Teacher Education, 24(1), 80-91.

Wang, T. (2015). Contrived collegiality versus genuine collegiality: Demystifying professional learning communities in Chinese schools. Compare, 45(6), 908-930.

Zhang, J., \& Pang, N.S.K. (2016). Investigating the development of professional learning communities: compare schools in Shanghai and Southwest China. Asia Pacific Journal of Education, 36(2), 217-230. 